\title{
Assessment of Preparedness for the COVID-19 Pandemic in Schools in Al-Rusafa District, Baghdad, Iraq, 2021
}

Marha Kamoona ${ }^{1}$, BDentSc, FETP; Deepak Kumar ${ }^{2}$; Alison Yoos $^{3}$; Bashar Abdul Latif $^{4}$; Ayad AL-Temeemy ${ }^{5}$; Safaa Al Ghanimy ${ }^{6}$

\footnotetext{
${ }^{1}$ International Health Regulations Section, Public Health Directorate, Iraqi Ministry of Health, Baghdad, Iraq

${ }^{2}$ Medical Epidemiologist and Public Health Management Expert, Improving Public Health Management for Action Program, Director IHA, New Delhi, India

${ }^{3}$ Improving Public Health Management for Action Program, African Field Epidemiology Network, Nairobi, Kenya

${ }^{4}$ Department of Public Health, Al-Rusafa Department of Health, Baghdad, Iraq

${ }^{5}$ Commission of Medical Tertiary Center, Iraqi Ministry of Health, Baghdad, Iraq

${ }^{6} \mathrm{CDC}$ Section, Karbala Department of Health, Karbala, Iraq
}

\section{Corresponding Author:}

Marha Kamoona, BDentSc, FETP

International Health Regulations Section

Public Health Directorate

Iraqi Ministry of Health

8/1 Falestin Street

Rusafa, Area 503

Baghdad, 10064

Iraq

Phone: 9647737593680

Email: kdr.marha@yahoo.com

\section{Abstract}

Background: Following the international spread of the novel coronavirus (SARS-CoV-2) or COVID-19 pandemic, the Iraqi government took several steps to prevent community transmission, including the indefinite closure of schools as a measure to safeguard schoolchildren from COVID-19. The key rationale behind these decisions was the insufficient preparedness level within schools to prevent infection and the lack of appropriate vaccines for children.

Objective: Researchers assessed COVID-19 preparedness levels in schools in Al-Rusafa district, Baghdad, to prepare schools for reopening.

Methods: An observational study design was conducted to assess the schools. Stratified sampling was performed to make the sample more representative; we stratified the schools into 3 categories based on sex, level (primary or secondary), and administration (public or private). The study population comprised all students and teachers in the selected sample. The assessment was carried out retrospectively for 3 months, from May 31, 2021. Data were collected through face-to-face interviews and analyzed using Microsoft Excel. Tables and pie charts were used to display the results.

Results: The assessment was completed in 40 schools-20 (50\%) primary schools, $10(25 \%)$ high schools, $6(15 \%)$ intermediate schools, and 4 (10\%) secondary schools. Overall, the assessment covered 1162 teachers and 16,776 students. The highest infection rate, according to school category, was among primary school staff $(6.14 \%)$. Moreover, $92 \%(n=39)$ of the schools did not have a contact number for a nearby ambulance, and early detection system was weak in $60 \%(n=24)$ of the schools, which reflected low levels of school participation in preparing against the COVID-19 pandemic. Referral system for any sick person to an appropriate health facility was not present or was disabled in $63 \%(n=25)$ of the schools.

Conclusions: The assessment concluded that none of the schools had a robust screening system to record students infected with COVID-19. The study discusses several actions and requirements that should be reviewed and addressed to prevent the spread of COVID-19 in the schools and the community.

(iproc 2022;8(1):e37304) doi: 10.2196/37304 


\section{KEYWORDS}

COVID-19; Al-Rusafa District; the spread of COVID-19; schools

\section{Multimedia Appendix 1}

COVID-19 infection rates among school staff according to type of school included in the assessment from 1/3-1/6 2021, Iraq /

Baghdad Rusafa .

[DOCX File, 17 KB-Multimedia Appendix 1]

\section{Multimedia Appendix 2}

Epidemiological factors for school staff and students in schools included in the assessment from 1/3-1/6 2021, Iraq / Baghdad Rusafa.

[DOCX File, 2077 KB-Multimedia Appendix 2]

\section{Multimedia Appendix 3}

Number of referred cases to PHCC, contact tracing, obligatory sick leave and total no. of confirmed cases from cases referred to PHCC for schools included in the assessment from 1/3 - 1/6 2021, Iraq / Baghdad, Rusafa.

[DOCX File, 2057 KB-Multimedia Appendix 3]

\section{Multimedia Appendix 4}

Health Services, Health promotion activities through social media, Hygiene practices and WASH services indicators followed by schools administrates in schools included in the assessment from 1/3-1/6 2021, Iraq, Baghdad, Rusafa.

[DOCX File, 20 KB-Multimedia Appendix 4]

\section{Multimedia Appendix 5}

Knowledge, Practice \& Attitude about isolation termination criteria and Quarantine Criteria followed by schools administrates in schools included in the assessment from 1/3-1/6 2021, Iraq / Baghdad, Rusafa.

[DOCX File, 14 KB-Multimedia Appendix 5]

\section{Multimedia Appendix 6}

COVID-19 daily new confirmed cases in Iraq from the first case 24/2/2020 till school reopening decision on 29/11/2020. [PNG File, 94 KB-Multimedia Appendix 6]

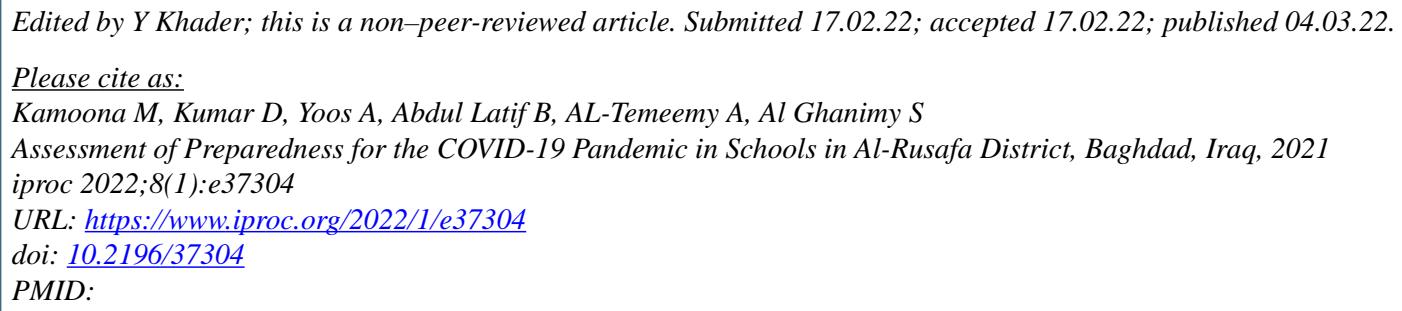

CMarha Kamoona, Deepak Kumar, Alison Yoos, Bashar Abdul Latif, Ayad AL-Temeemy, Safaa Al Ghanimy. Originally published in Iproceedings (https://www.iproc.org), 04.03.2022. This is an open-access article distributed under the terms of the Creative Commons Attribution License (https://creativecommons.org/licenses/by/4.0/), which permits unrestricted use, distribution, and reproduction in any medium, provided the original work, first published in Iproceedings, is properly cited. The complete bibliographic information, a link to the original publication on https://www.iproc.org/, as well as this copyright and license information must be included. 